\title{
Pembuatan Khotbah dan Buku Advokasi Anti Kekerasan Perempuan Pada JEMAAT MANEORATU
}

\author{
${ }^{1}$ Resa Dandirwalu, ${ }^{2}$ Yanes Parihala, ${ }^{3}$ Tri Astuti Relmasira, ${ }^{4}$ Yohanes Sinay

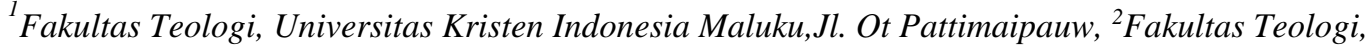 \\ Universitas Kristen Indonesia Maluku,Jl. Ot Pattimaipauw, ${ }^{3}$ Fakultas Teologi, Universitas Kristen \\ Indonesia Maluku,Jl. Ot Pattimaipauw, ${ }^{4}$ Fakultas Teologi, Universitas Kristen Indonesia Maluku,Jl. Ot \\ Pattimaipauw \\ email: ${ }^{1}$ resadandirwalu@ukim.ac.id, ${ }^{2}$ parihalayoh@gmail.com, ${ }^{3}$ tutyrel@gmail.com, \\ 4sinayanesco@gmail.com
}

\begin{abstract}
The purpose of this community service is to increase the knowledge and skill of women in the GPM Congregation of Maneoratu about preaching on nonviolence issues and the advocacy book for women, as an effort to avoid women from violent behavior. The method was the community relation which was done in five phases: 1) Meeting the partners to discuss the main issues, got the permit and support for the implementation; 2) Socializing preaching of non-violence; 3) Socializing the making of Advocacy Book for women; 4) Exercising of composing the non-violence sermons to women and making the advocacy manuals; and 5) Evaluating and Follow-up. This community service involved the partner, namely the GPM Congregation of Maneoratu, Klasis GPM Telutih, which was held on September $5^{\text {th }}$ - November $11^{\text {th }}$, 2019. The result obtained was partner experiencing the increase of knowledge about non-violence sermons and advocacy books for women, and partner was increasingly skilled to compose non-violence sermons and advocacy books on women in the GPM Congregation of Maneoratu, so that the behavior of non-violence against women was developed in the congregation.
\end{abstract}

Keywords: Preaching/Sermon, Non-violence, Advocacy, Women, GPM Congregation of Maneoratu.

\begin{abstract}
Abstrak. Tujuan pengabdian ini adalah meningkatkan pengetahuan dan ketrampilan perempuan di Jemaat GPM Maneoratu, tentang khotbah anti kekerasan dan buku advokasi bagi perempuan, sebagai upaya untuk menghindari perempuan dari perilaku-perilaku kekerasan, dan metodenya adalah community relation, dengan 5 tahapan, yaitu: (1), menemui mitra untuk membahas permasalahan utama, memperoleh izin dan dukungan pelaksanaan; (2), sosialisasi khotbah anti kekerasan. (3), Sosialisasi Pembuatan Buku Advokasi bagi Perempuan; (4), pelatihan pembuatan khotbah anti kekerasan terhadap Perempuan dan pembuatan buku petunjuk advokasi; dan (5), evaluasi dan tindak lanjut. Pengabdian melibatkan Mitra, yaitu: Jemaat GPM Maneoratu, Klasis GPM Telutih, yang berlangsung pada tanggal 05 September - 11 November 2019. Hasil yang diperoleh setelah pelaksanaan pengabdian adalah mitra mengalami peningkatan pengetahuan tentang khotbah anti kekerasan dan buku advokasi terhadap perempuan, dan mitra semakin terampil untuk membuat khotbah anti kekerasan dan buku advokasi terhadap perempuan di Jemaat GPM Maneoratu, sehingga terciptanya perilaku anti kekerasan terhadap perempuan dalam jemaat.
\end{abstract}

Kata Kunci. Khotbah, Anti Kekerasan, Advokasi, Perempuan, Jemaat GPM Maneoratu. 


\section{Pendahuluan}

Kekerasan terhadap perempuan seringkali dialami perempuan dengan berbagai kasusnya, seperti kasus pemerkosaan, pelecehan seksual, dan eksploitasi seksual, karena berdasarkan data yang dikeluarkan oleh Komisi Nasional Perempuan, tergambar bahwa jumlah kekerasan terhadap perempuan sebanyak 400.939, dalam kurun waktu 13 tahun (1998-2011), dengan perincian sebagai berikut: kasus pemerkosaan 4.845 kasus, dan kasus kekerasan seksual 93.960 kasus, sedangkan di Provinsi Maluku pada tahun 2017 terdapat 198 kasus kekerasan yang dialami perempuan, seperti kekerasan dalam rumah tangga 108 kasus, kasus kekerasan seksual perkosaan sebanyak 45 kasus dengan rata-rata usia korban 3-17 tahun, kasus pelecehan seksual 20 kasus, dan kasus cabul sebanyak 20 kasus dengan usia berkisar 2-10 tahun.

Jemaat GPM Maneoratu merupakan salah satu jemaat di Klasis GPM Telutih, yang mengalami konflik sosial tahun 1999, sehingga harus mengungsi ke hutan selama satu bulan, kemudian mereka ditolong oleh Relawan dari Gereja Baptis menuju ke wilayah Seram Utara dan Waipia hingga tahun 2005 barulah mereka kembali ke lokasi semula (Negeri Maneoratu), sehingga saat ini masih bermukim di perumahan bantuan Dinas Sosial (Semi Permanen). Kemudian, secara geografi, sebelah Utara, Jemaat GPM Maneoratu berbatasan dengan Hutan Seram Utara, Sebelah Timur berbatasan dengan Negeri Laimu, Sebelah Barat berbatasan dengan Anak Dusun Negeri Tehua, dan sebelah Selatan berbatasan dengan Laut Banda.

Selanjutnya, untuk sampai ke Jemaat GPM Maneoratu, bisa ditempuh dengan kendaraan beroda empat dan beroda dua selama kurang lebih 5 jam dari Ambon, dan 3 Jam dari Masohi, selain itu bisa menggunakan katinting, jonson, dll, dari Tehoru selama kurang lebih dua jam.

$$
\text { Jemaat GPM Maneoratu }
$$

termasuk Jemaat yang tergolong miskin, karena pendapatan mereka hanya pada hasil panen tanaman umur panjang, seperti kelapa, dan cengkih, sehingg mereka hanya bisa mengkonsumsikan makanan tradisional seperti papeda untuk mempertahankan hidup, dan Jemaat GPM Maneoratu diperhadapkan dengan sistem ijon yang turut mewarnai kehidupan umat di Jemaat GPM Maneoratu, contohnya, umat diberikan pinjaman sebesar Rp.150.000 oleh pengusaha untuk membiayai kebutuhan mereka dengan syarat adalah tanaman umur panjang seperti kelapa dan cengkih yang berada di dusun akan dipanen oleh pengusaha tersebut selama beberapa tahun.

Berdasarkan hasil observasi awal, di Jemaat GPM Maneoratu, terkait dengan masalah kekerasan perempuan, maka ditemukan bahwa kekerasan perempuan cenderung berlangsung di Jemaat GPM Maneoratu, dan dianggap sebagai sesuatu yang biasa saja karena bukanlah masalah yang harus ditangani di Jemaat GPM Maneoratu, sehingga menurut Hairani Siregar (2015), kekerasan perempuan sulit terungkap karena kekerasan perempuan dianggap masalah yang tidak perlu diungkapkan sebab tidak ada penyelesaiannya dan perempuan sebagai korban selalu disalahkan, bahkan sosialisasi masalah kekerasan belum menyeluruh ke semua lapisan dan pemangku kebijakan, sehingga belum ada tindakan yang efektif bagi perempuan yang mengalami kekerasan. Kekerasan tersebut diakibatkan oleh Jemaat GPM Maneoratu merupakan Jemaat yang masih mempertahankan sistem 
patriakhi, dimana laki-laki sangat dijunjung tinggi dan tidak diperkenankan melakukan aktivitas yang dianggap rendah, seperti mengasuh anak, mencuci, memasak, dan berkebun. Akan tetapi, semua aktivitas tersebut hanya dilakukan oleh perempuan, mulai dari mengasuh anak sampai pada aktivitas di kebun, sedangkan laki-laki cenderung mengkonsumsikan minuman keras (sopi), sehingga berpengaruh negatif terhadap sikap dan perilaku mereka, seperti memukul, melempari, dan melukai perempuan (istri), perempuan tidak bisa membalas perilaku yang dialami, karena takut dikatakan perempuan yang tidak tahu adat, dan tingkat pendidikan mereka yang terbatas, karena hanya tamatan Sekolah Dasar (SD), sehingga perempuan sering hidup dalam ketidaknyamanan dan ketidaktenteraman akibat kekerasan yang cenderung dialami perempuan di Jemaat GPM Maneoratu.

Selama ini, perempuan di Jemaat GPM Maneoratu belum memiliki pengetahuan yang memadai tentang kekerasan dalam rumah tangga, karena belum pernah dilakukan transfer pengetahuan dari pihak gereja kepada mereka, dan proses pendampingan yang terprogram disertai dengan buku petunjuk advokasi belum dilakukan dan dimiliki oleh pihak gereja di Jemaat GPM Maneoratu. Karena itu, berdasarkan hasil wawancara dan kesepakatan bersama antara Tim dengan Mitra, maka masalah utama adalah perempuan di Jemaat GPM Maneoratu belum memiliki pengetahuan yang memadai tentang kekerasan dalam rumah tangga, sebab belum pernah dilakukan transfer pengetahuan dari pihak gereja kepada mereka; dan Jemaat GPM Maneoratu belum memiliki Buku Petunjuk Advokasi bagi Perempuan.
Program ini bertujuan untuk meningkatkan pengetahuan dan ketrampilan perempuan di Jemaat GPM Maneoratu, tentang khotbah anti kekerasan dan buku advokasi bagi perempuan, sebagai upaya untuk menghindari perempuan dari perilakuperilaku kekerasan, sehingga hasil dari program ini adalah adanya peningkatan kapasitas pengetahuan dan ketrampilan dari perempuan di Jemaat GPM Maneoratu mengenai pencegahan dengan perilaku-perilaku yang anti kekerasan terhadap perempuan.

\section{Metode}

Program Pengabdian melibatkan Mitra, yaitu: Jemaat GPM Maneoratu, Klasis GPM Telutih, yang berlangsung pada tanggal 05 September - 11 November 2019, dan menggunakan metode community relation, dengan 5 tahapan kegiatan, yaitu: pertama, menemui mitra untuk membahas permasalahan utama, memperoleh izin dan dukungan pelaksanaan; kedua, sosialisasi khotbah anti kekerasan; ketiga, sosialisasi pembuatan buku advokasi bagi perempuan; keempat, Pelatihan Pembuatan khotbah anti kekerasan terhadap perempuan dan pembuatan buku petunjuk advokasi; dan kelima, evaluasi dan tindak lanjut.

\section{Hasil dan Pembahasan}

Peserta yang mengikuti pengabdian berjumlah 47 orang: lakilaki 20 orang dan perempuan 27 orang, bertempat di gedung gereja Exodus Jemaat GPM Maneoratu, dari pukul 10.00 hingga 15.00 WIT. Pengabdian kepada peserta (mitra) dilakukan dengan dua model, yaitu model sosialisasi dan model pelatihan, dan selalu diikuti oleh 47 peserta dari awal hingga akhir, yang ditunjukan melalui absen kegiatan pada setiap sesi; baik 
sesi sosialisasi, maupun sesi pelatihan, tampak pada gambar 1 di bawah ini.

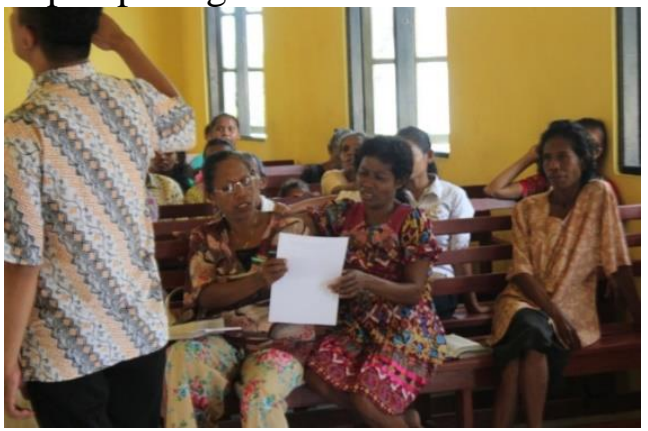

Gambar 1. Pengisian Absen

Sumber: Dokumentasi Tim Pengabdian, 2019

\section{Tahap Pertama: Menemui Mitra}

Tahap ini, dilakukan pertemuan dengan Ketua Majelis Jemaat GPM Maneoratu, untuk membahas permasalahan utama yang sedang dihadapi, yaitu: perempuan di Jemaat GPM Maneoratu belum memiliki pengetahuan yang memadai tentang kekerasan dalam rumah tangga, dan belum memiliki buku petunjuk advokasi bagi perempuan.

Tahap ini berlangsung dengan sangat baik, karena mitra bersedia menerima dan memberikan dukungan kepada tim untuk melaksanakan pengabdian dengan mereka, sehingga pengabdian boleh berlangsung pada tanggal 05 September - 11 November 2019, di Jemaat GPM Maneoratu.

Tahap Kedua: Sosialisasi Khotbah Anti Kekerasan

Sosialisasi Khotbah Anti

Kekerasan diikuti oleh 47 peserta, dan berlangsung pada pukul $10.00-12.00$ WIT, di Gedung Gereja Exodus Jemaat GPM Maneoratu, dengan menggunakan metode ceramah, tanya jawab, dan diskusi. Metode tersebut ditunjang dengan alat peraga berupa potongan kertas HVS, dan LCD Projector, untuk membantu proses penyajian materi, sehingga peserta sangat antusias untuk mendengar dan mengikuti materi Khotbah Anti Kekerasan yang disampaikan, seperti yang ditunjukan pada gambar 2 di bawah ini.

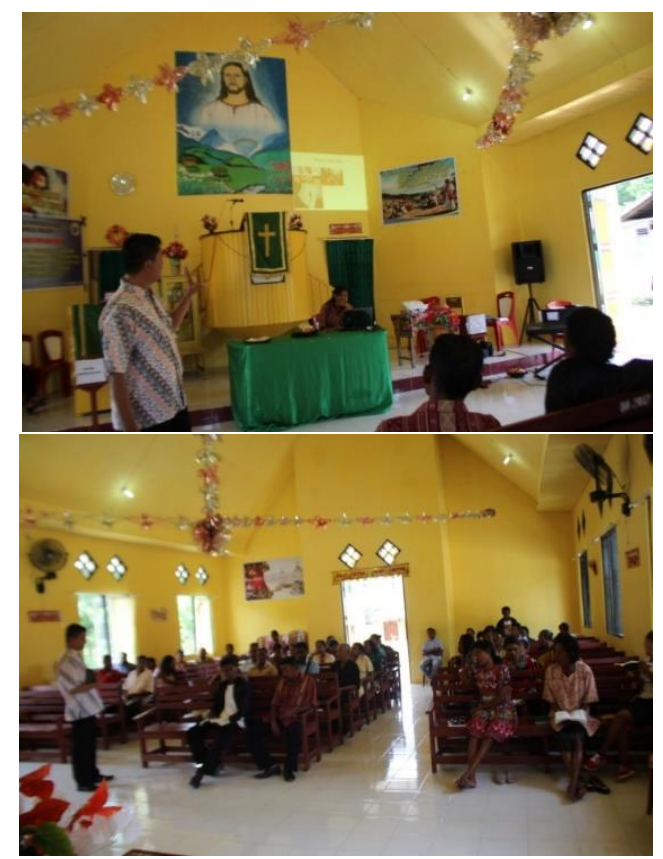

Gambar 2. Model, Alat Peraga, dan Antusias Peserta selama Sosialisasi

Sumber: Dokuemntasi Tim Pengabdian, 2019

Materi Anti Kekerasan ditekankan pada beberapa aspek, yaitu: pertama, memberikan pengertian kekerasan, tipologi kekerasan: kekerasan langsung, kekerasan struktural, dan kekerasan kultural); dan kedua, menunjukan teks-teks Alkitab yang apabila tidak ditafsirkan, maka dapat menimbulkan kekerasan, melanggengkan kekerasan, dan melegitimasi kekerasan terhadap perempuan, seperti teks Amsal 31: 1031, I Korintus 14: 34-35, dan Efesus 5: 22-35.

Selama proses penyajian materi, adanya interaksi yang ditunjukan oleh peserta sangat baik dan aktif serta dinamis dalam meresponi pertanyaanpertanyaan yang disampaikan oleh Fasilitaor, khususnya pertanyaan yang berhubungan dengan pengalaman kekerasan yang dialami. Peserta sangat terbuka untuk menyampaikan 
pengalaman-pengalaman kekerasan yang selama ini dialami, baik oleh lakilaki maupun perempuan; selain itu, peserta diberikan kesempatan untuk membaca teks Alkitab Amsal 31: 10-31, I Korintus 14: 34-35, dan Efesus 5: 2235 , kemudian memberikan pandangan yang berhubungan dengan anti kekerasan, dan pandangan mereka cukup baik karena sudah bisa memberikan pandangan yang mengandung perilaku anti kekerasan, sebagaimana terlihat pada gambar 3 di bawah ini.

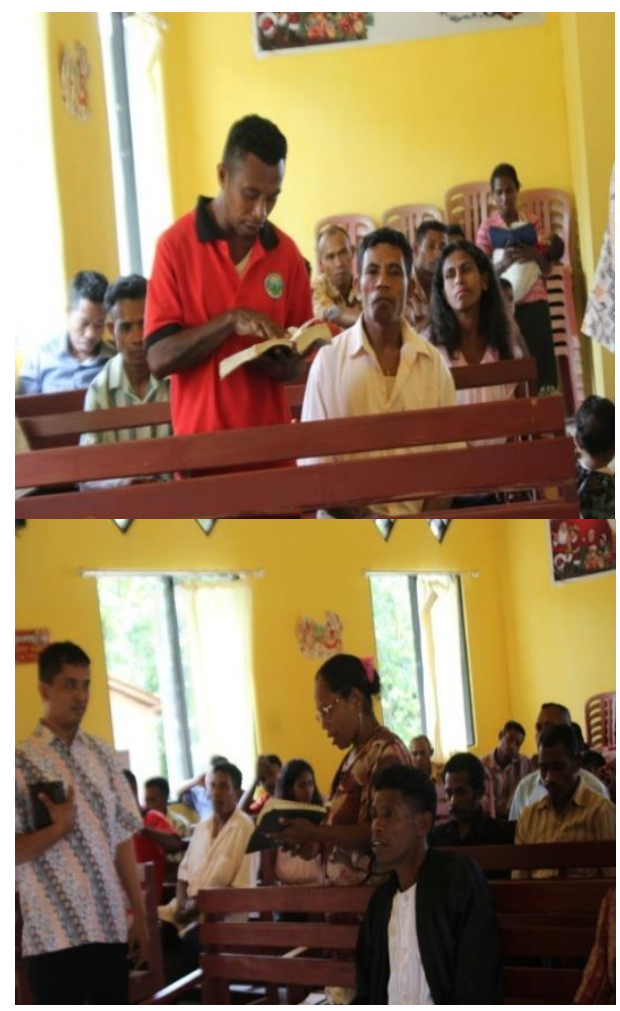

Gambar 3.Peserta Membaca Teks Alkitab dan Memberikan Pandangan Sumber: Dokuemntasi Tim Pengabdian, 2019

\section{Hasil Evalusi Kegiatan Sosialisasi Anti Kekerasan}

Model evaluasi yang dilakukan adalah wawancara, yaitu tim memberikan dua pertanyaan kepada peserta untuk dijawab, yaitu: pertama, berikanlah contoh pengalaman kekerasan yang selama ini dialami, baik kepada istri, suami, maupun anak-anak; dan kedua, berikanlah pandangan tentang teks-teks Alkitab yang terkesan mengandung kekerasan, khususnya kekerasan kepada perempuan. Peserta dapat menjawab kedua pertanyaan tersebut dengan baik, sehingga terlihat adanya peningkatan pengetahuan dari peserta terkait dengan khotbah anti kekerasan kepada perempuan, maka apabila hasil tersebut dikuantitatifkan, terlihat $85 \%$ dari 47 peserta yang hadir telah memiliki pengetahuan yang baik tentang anti kekerasan di Jemaat GPM Maneoratu.

Tahap Ketiga: Sosialisasi Pembuatan Buku Advokasi bagi Perempuan

Materi sosialisasi ini, berlangsung pada pukul 12.00-14.00, dengan metode yang dipergunakan adalah ceramah, tanya jawab, dan diskusi. Metode tersebut ditunjang dengan media LCD Projector, selain itu, posisi tempat duduk yang berbentuk huruf $U$, sehingga memudahkan peserta saling berinteraksi dan memudahkan penyerapan materi yang disampaikan, agar tujuan sosialisasi dapat tercapai, sebagaimana ditunjukan pada gambar 4 di bawah ini.

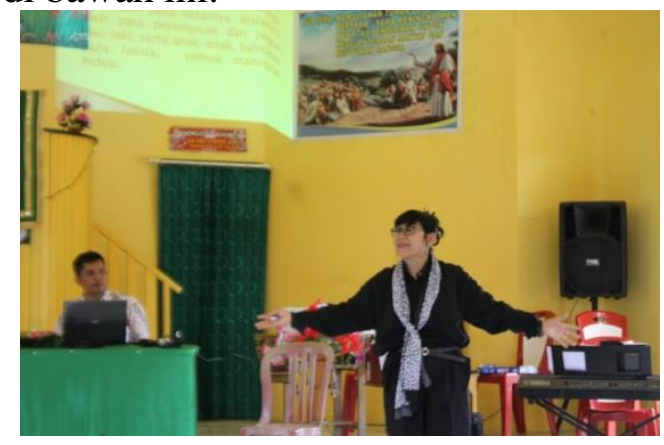

\section{Gambar 4. Penyajian Materi Pembuatan Buku Advokasi bagi Perempuan}

Sumber: Dokuemntasi Tim Pengabdian, 2019

Mengawali sosialisasi Pembuatan Buku Advokasi bagi Perempuan, Fasilitator mengajak peserta untuk melakukan permainan, yaitu: mata dari seorang Bapak ditutup 
dengan kain hitam, dan peserta diarahkan untuk memberikan petunjuk kepadanya. Petunjuk tersebut adalah Bapak tersebut harus bisa berjalan sekitar 5 meter, menuju ke papan tulis dan mengambil sepidol untuk menggambarkan manusia, dan akhirnya berhasil, tampak pada gambar 4 di bawah ini.

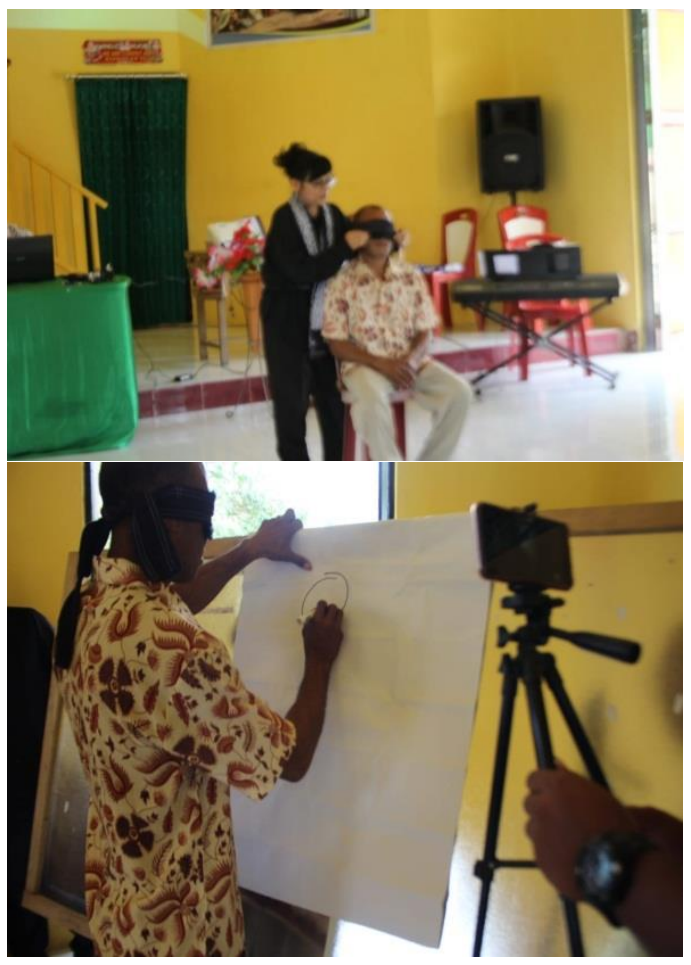

Gambar 5. Permainan diawal materi Sumber: Dokuemntasi Tim Pengabdian, 2019

Susudah itu, Fasilitaor menyampaikan pesan dari permainan tersebut yaitu: peran pendampingan menjadi sangat penting, untuk menghentarkan orang lain supaya dapat melakukan berbagai tindakan anti kekerasan di dalam hidupnya. Pesan itulah yang melatari pembuatan Buku Advokasi bagi Jemaat GPM Maneoratu, sehingga sosialisasi menjadi penting, maka materi sosialisasinya terkait dengan empat (4) langkah, yaitu: langkah 1 adalah Pemahaman Dasar, yaitu: kebutuhan dan kepedulian, perasaan dan ketakutan terhadap kekerasan pada dasarnya dialami oleh para perempuan dan juga laki-laki, serta anak-anak, bahkan para lansia; langka 2 adalah Tujuan Pendampingan, yaitu: membangun partnership atau jalinan hubungan kebersamaan yang seimbang positif, sehat, saling menghargai berdasarkan bukan kuasa tetapi relasi yang sehat; langka 3 adalah Identifikasi Kekerasan, yaitu: mengedepankan semua kemungkinan terjadinya luka, dukacita, sakit atau bahkan kematian akibat kekerasan; dan langkah 4 adalah Kekerasan secara Eksegetis, yaitu: tindakan manusia yang merusak hubungan manusia dengan Allah dan menghancurkan ciptaan-NYA. Setiap langkah yang dijelaskan selalu disertai dengan contoh, baik dari Fasilitator maupun dari peserta, sehingga peserta semakin mengerti dan memahami manfaat keberadaan buku advokasi bagi perempuan, agar membantu mereka dalam proses pendampingan untuk terciptanya anti kekerasan dalam kehidupan mereka.

Berdasarkan hasil pengamatan, peserta sangat antusias dalam mengikuti sosialisasi yang diberikan, karena dengan metode yang bervariasi turut menghidupi suasana selama proses sosialisasi, sehingga tidak ada peserta yang beranjak dari tempat duduk mereka. Materi diakhiri dengan permainan berupa setiap peserta diberikan sedotan dan gelang karet, kemudian diberikan kertas yang bertuliskan "kami berjanji untuk selalu melakukan tindakan anti kekerasan kepada suami, istri, anak-anak", sebagai bentuk komitmen untuk melakukan tindakan anti kekerasan, dan diestafet dari peserta bagian depan hingga ke peserta bagian belakang. Fasilitator memberikan makna dari permainan tersebut, yakni: pendampingan kepada sesama untuk meneruskan perilaku hidup anti kekerasan terus dilakukan secara kontinyu, sehingga korban 
kekerasan tidak dijumpai dalam kehidupan ber-jemaat, khususnya di Jemaat GPM Maneoratu, seperti pada gambar 6 di bawah ini.

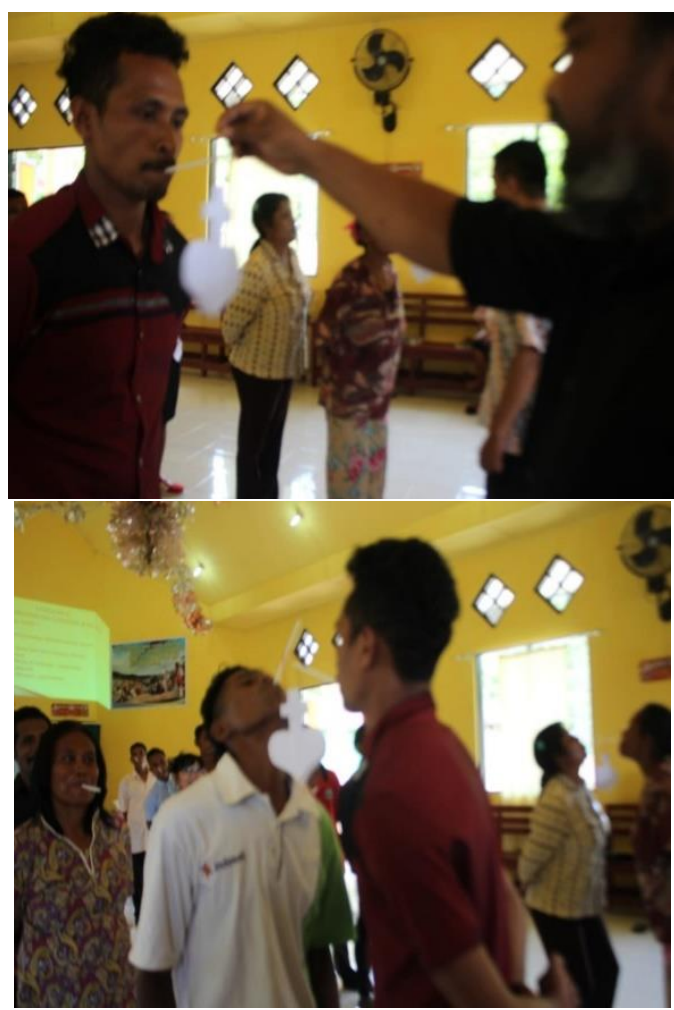

Gambar 6. Permainan Estafet Sedotan

Sumber: Dokuemntasi Tim Pengabdian, 2019

\section{Hasil Evalusi Kegiatan Sosialisasi Pembuatan Buku Advokasi Bagi Perempuan}

Metode

evaluasi yang

dipergunakan adalah wawancara, artinya Fasilitator memberikan pertanyaan kepada peserta dan dijawab oleh mereka, pertanyaan tersebut adalah sebutkan empat langkah disertai dengan contoh dalam proses pembuatan buku advokasi, dan dapat dijawab dengan baik oleh peserta yang hadir, sehingga peserta cukup mengerti dan memahami materi yang disajikan oleh Fasilitator, terkait dengan pembuatan buku advokasi bagi perempuan. Apabila hasil tersebut dikuantitatifkan, maka $85 \%$ dari 47 peserta yang hadir telah memiliki pemahaman yang baik tentang pembuatan buku advokasi bagi perempuan di Jemaat GPM Maneoratu.

Tahap Empat: Pelatihan Pelatihan Pembuatan khotbah anti kekerasan terhadap Perempuan dan Pembuatan Buku Petunjuk Advokasi

Pelatihan Pembuatan khotbah anti kekerasan dan buku petunjuk advokasi berlangsung pada pukul 14.00 hingga 15.00 WIT, di gedung gereja Exodus, Jemaat GPM Maneoratu, kemudian peserta dibagi menjadi tiga kelompok. Setiap kelompok diberikan dua tugas, yaitu: tugas pertama, setiap kolempok diberikan teks Alkitab yang berbeda-beda untuk membuat khotbah, yaitu: kelompok 1 teks Amsal 31: 1031; kelompok 2 teks I Korintus 14: 3435; dan kelompok 3 teks Efesus 5: 2235. Tugas kedua, setiap kelompok diberikan konsep yang berbeda untuk dikerjakan, yaitu: kelompok 1 mengerjakan pengalaman-pengalaman kekerasan yang selama ini ditemui dan dialami, kelomok 2 mengerjakan pengalaman advokasi yang dilakukan selama ini, dan kelompok 3 mengerjakan model-model pendampingan ke depan. Ketiga kelompok diberikan waktu selama 45 menit untuk menyelesaikannya, dan dipresentasikan selama 15 menit di hadapan kelompok lainnya dan tim.

Selama kelompok mengerjakan dua tugas yang diberikan, tampak keseriusan dan antusias yang tinggi ditunjukan oleh setiap kelompok, mereka saling berdiskusi, saling bersenda gurau di antara mereka, kemudian tim selalu mendampingi untuk memberikan arahan dan masukan kepada setiap kelompok untuk memudahkan proses pengerjaan mereka. Pendampingan tersebut berlangsung dengan baik dan diresponi positif oleh setiap kelompok, sesudah itu, setiap kelompok mempresentasikannya di hadapan 
kelompok lainnya dan tim, kemudian tim memberikan evaluasi terhadap hasil yang dipresentasikan tersebut, sebagaimana terlihat pada gambar 7 di bawah ini.

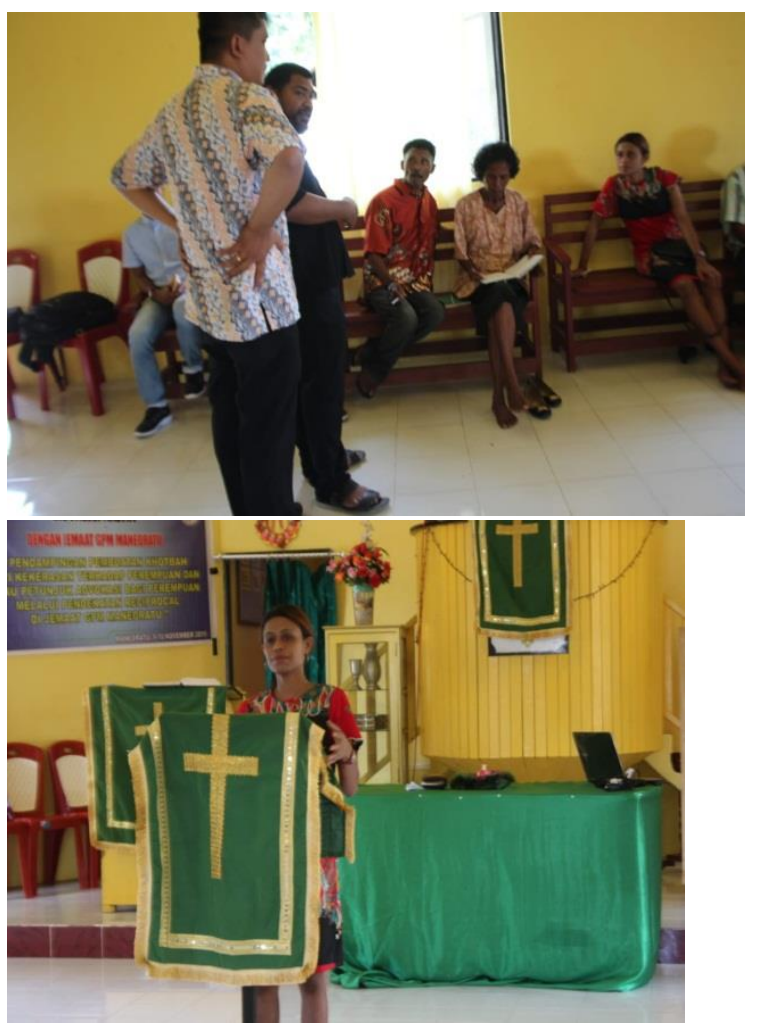

Gambar 7. Pendampingan Tim pada Kelompok dan Presentasi Kelompok Sumber: Dokuemntasi Tim Pengabdian, 2019

\section{Hasil Evalusi Kegiatan Sosialisasi Pembuatan Buku Advokasi Bagi Perempuan}

Evaluasi yang dilakukan bertolak pada hasil kerja kelompok yang dipresentasikan di depan kelompok lainnya, sehingga ditemukan bahwa peserta sudah bisa membuat khotbah anti kekerasan dengan baik, meskipun belum sempurna, dan peserta sudah bisa mengidentifikasi masalah kekerasan dan penangannya selama ini, serta menemukan model-model advokasi ke depan untuk dijadikan buku pegangan advokasi. Apabila hasil yang diperoleh tersebut, dikuantitatifkan, maka $85 \%$ peserta telah memiliki kemampuan untuk membuat khotbah anti kekerasan dan buku pegangan advokasi bagi perempuan di Jemaat GPM Maneoratu.

Tahap Lima: Evaluasi dan Tindak Lanjut

Kegiatan sosialisasi dan pelatihan pembuatan khotbah anti kekerasan dan pembuatan buku advokasi dikatakan berhasil, karena berdasarkan hasil evaluasi dengan mitra, mereka memandang bahwa kegiatan sosialisasi dan pelatihan yang diikuti memberikan kontribusi yang tinggi dan memuaskan karena baru pertama kali diikuti, maka informasi yang belum pernah diperoleh sebelumnya dapat diketahui dengan baik. Karena itu, tindak lanjut dari kegiatan ini adalah kerjasama dan komunikasi terus terbina antara tim dengan Mitra melalui perjumpaan di Jemaat GPM Maneoratu dan jaringan seluler (HP), agar khotbah anti kekerasan kepada perempuan terus dilakukan, dan buku pegangan advokasi bagi perempuan dapat dimiliki oleh Jemaat GPM Maneoratu.

\section{Kesimpulan dan Saran}

Dengan berakhirnya kegiatan sosialisasi dan pelatihan melalui Pengabdian kepada Masyarakat, maka kesimpulannya adalah Peserta sosialisasi mengalami peningkatan pengetahuan tentang khotbah anti kekerasan dan buku advokasi terhadap perempuan, dan Peserta semakin terampil dalam membuat khotbahkhotbah anti kekerasan dan membuat buku advokasi bagi perempuan. Kiranya Institusi Gereja, khususnya di Jemaat GPM Maneoratu terus melakukan pembinaan, pendampingan dan pastoral, kepada anggota jemaat, sehingga dapat mempraktekan tindakan dan perilaku anti kekerasan baik kepada istri, suami, maupun anak-anak. 


\section{DAFTAR PUSTAKA}

Purwanti Rachma. Peningkatan Kapasitas Kader Posyandu: Cegah Stunting Dengan Perbaikan Gizi 1000 HPK. Jurnal Ethos: Jurnal Penelitian dan Pengabdian kepada Masyarakat, Vol. 17, No.2, Juni 2019:

https://ejournal.unisba.ac.id > ethos > article > view, diakses tanggal 15 Agutsus 2019

Tuasela Dessy, Janes Parihala. Pelayanan Pastoralia Transformatif Untuk Penanganan Masalah Kekerasan Seksual Terhadap Perempuan Di Ambon Wawasan: Jurnal Ilmiah Agama dan Sosial Budaya 2, 2 (Desember 2017): 167. journal.uinsgd.ac.id/index.php/jw, diakses tanggal 20 Juli 2018

Renstra Jemaat GPM Maneoratu Tahun 2016-2020 (tidak diterbitkan)

Siregar Hairani, Bentuk-Bentuk Kekerasan Yang Dialami Perempuan Warga Komplek Dinas Peternakan Provinsi Sumatera Utara. Jurnal Ilmu Kesejahteraan Sosial Vol. 14, No. 1, Juni 2015: 11 https://jurnal.usu.ac.id/index.php/jur nalpemberdayaan/article/.../664...dia kses tanggal 20 Juli 2018

Sakina Irma Ade dan Dessy Hasanah Siti A. Menyoroti Budaya Patriarki Di Indonesia. Social Work Jurnal, Vol. 7, No.1, 2017: 1. jurnal.unpad.ac.id > share > article > view. Diakses tanggal 20 Juli 2018 https://infoambon.com/2018/05/28/2017-ada207-kasus-kekerasan-terhadapperempuan-dan-anak-di-maluku/, diakses tanggal 20 Juli 2018. 